\title{
Fabrication of the Textured Ni-9.3at.\%W Alloy Substrate for Coated Conductors
}

Gao, M. M.; Suo, H. L.; Grivel, Jean-Claude; Yue, Zhao; Gao, P. K.; Liu, M.; Ma, L.

Published in:

I E E E Transactions on Applied Superconductivity

Link to article, DOI:

10.1109/TASC.2011.2105850

Publication date:

2011

Document Version

Publisher's PDF, also known as Version of record

Link back to DTU Orbit

Citation (APA):

Gao, M. M., Suo, H. L., Grivel, J-C., Yue, Z., Gao, P. K., Liu, M., \& Ma, L. (2011). Fabrication of the Textured Ni9.3at.\%W Alloy Substrate for Coated Conductors. I E E E Transactions on Applied Superconductivity, 21(3), 2969-2972. https://doi.org/10.1109/TASC.2011.2105850

\section{General rights}

Copyright and moral rights for the publications made accessible in the public portal are retained by the authors and/or other copyright owners and it is a condition of accessing publications that users recognise and abide by the legal requirements associated with these rights.

- Users may download and print one copy of any publication from the public portal for the purpose of private study or research.

- You may not further distribute the material or use it for any profit-making activity or commercial gain

- You may freely distribute the URL identifying the publication in the public portal 


\title{
Fabrication of the Textured Ni-9.3at.\%W Alloy Substrate for Coated Conductors
}

\author{
M. M. Gao, H. L. Suo, J.-C. Grivel, Y. Zhao, P. K. Gao, M. Liu, and L. Ma
}

\begin{abstract}
It is difficult to obtain a sharp cube texture in the Ni-9.3at.\% W substrate used for coated conductors due to its low stacking fault energy. In this paper, the traditional cold rolling procedure was optimized by introducing an intermediate recovery annealing. The deformation texture has been improved after three recovery annealing cycles at $500^{\circ} \mathrm{C}$ for $2 \mathrm{~h}$ during the cold rolling process. After optimized recrystallization annealing, a Ni-9.3at.\% substrate with a cube texture content of $87.7 \%\left(<10^{\circ}\right)$ has been obtained. The effect of the intermediate annealing on cube texture formation is attributed to the improved deformation texture and to the enhanced pre-existing cube oriented structure in the deformed matrix.
\end{abstract}

Index Terms-Coated conductor, cube texture, intermediate annealing, substrate.

\section{INTRODUCTION}

$\mathbf{F}$ OR the Ni-based alloys employed for fabrication of the metallic textured substrates, an excellent recrystallization cube texture and a non-ferromagnetic behavior at the application temperature of $77 \mathrm{~K}$ are the basic requirements for the epitaxial growth of buffer/YBCO coated conductors, and are expected to eliminate the magnetization losses in alternating current applications. Furthermore, a sufficiently high tensile strength at elevated preparation temperature is also necessary to ensure continuous multi-step reel to reel deposition processing. Thus, the Ni-9.3at.\%W (Ni9W) alloy is of great interest due to its high yield strength and non-ferromagnetic properties at the operating temperature $(77 \mathrm{~K})$ of coated conductors. Nevertheless, a perfect sharp cube texture is very difficult to produce because of the high $\mathrm{W}$ content, resulting in a drastic decrease of the stacking fault energy (SFE). The deformation texture has been changed from copper-type (pure Ni) to Brass-type (Ni9W) [1], [2]. The

Manuscript received August 01, 2010; accepted January 03, 2011. Date of publication February 17, 2011; date of current version May 27, 2011. This work was supported by the National Basic Research Program 973 of China (2006CB601005), National Natural Science Foundation of China (50771003), National High Technology Research and Development Program of 863 (2009AA032401), Beijing Municipal Natural Science Foundation (2092006) and Danish Agency for Science Technology and Innovation (Project 09-065234).

M. M. Gao is with both the College of Materials Science and Engineering, Beijing University of Technology, Beijing 100124, People's Republic of China. $\mathrm{He}$ is also with the Materials Research Division, Risø National Laboratory for Sustainable Energy, Technical University of Denmark, 4000 Roskilde, Denmark.

H. L. Suo, P. K. Gao, L. Ma, and M. Liu are with the College of Materials Science and Engineering, Beijing University of Technology, Beijing 100124, China (e-mail: honglisuo@bjut.edu.cn).

J.-C. Grivel and Y. Zhao are with the Materials Research Division, Risø National Laboratory for Sustainable Energy, Technical University of Denmark, 4000 Roskilde, Denmark.

Color versions of one or more of the figures in this paper are available online at http://ieeexplore.ieee.org.

Digital Object Identifier 10.1109/TASC.2011.2105850 relevant characteristics of a metallic substrate which can produce the sharp texture is the existence of the Copper-type deformation texture which is dominated by $\mathrm{C}$ and $\mathrm{S}$ orientations. Note that the main effect of the cube texture formation in Ni9W alloy is to inhibit the deformation texture transition, and thus to increase the intensity of $\mathrm{C}$ and $\mathrm{S}$ orientation which are related to the nucleation frequency and the grain growth of cube texture.

The origin of cube texture formation in face-centered cubic (fcc) materials has been developed and debated for several decades, and the opinion has focused on two alternative models, oriented nucleation $(\mathrm{ON})$ and oriented growth $(\mathrm{OG})$ [3]-[5]. According to the ON mechanism, the origin of cube texture lies in the preferred nucleation of cube grains from pre-existing cube-oriented structure in the deformed materials. In contrast, the cube texture development is attributed to the selective growth of grains with specific orientation. In order to obtain a sharp cube texture in Ni9W alloys, several processing techniques have been employed to increase the stacking fault energy or to optimize the deformation texture and pre-existing cube oriented structure in the deformed matrix. Zhou Y.X. et al. [6] have improved the cube texture content to $90 \%\left(<10^{\circ}\right)$ by powder metallurgy, due to the high energy ball milling which can increase the SFE of the Ni9W alloy. Eickemeyer J. et al. [7] have found out that the chemical homogeneity of the alloy and stress relief annealing during cold rolling process is beneficial for strengthening the cube texture in the Ni-W alloy ( $>$ at. $\% \mathrm{~W}$ ) with medium to low SFE. Furthermore, the deformation texture of Ni9W alloy can be optimized to a more copper-type deformation texture by warm rolling, therefore increasing the cube texture to $93 \%$ [8]. In our previous work [9], a special rolling technique (referred to as the intermediate recovery annealing during the cold rolling process) has been successfully carried out to form a sharp cube texture in Ni-7at.\%W alloy substrate.

In the present work, the intermediate recovery annealing has also been employed to strengthen the cube texture in Ni9W substrates. Due to the lower SFE compared to Ni7W alloy, more annealing cycles during cold rolling (multi-cycle recovery treatment) have been performed in Ni9W alloy tapes to produce the sharp cube texture. The evolution of deformation texture and cube texture has been investigated through the recovery cycles.

\section{EXPERIMENT}

The electrolytic nickel pieces (99.95\%) and $\mathrm{W}$ bulk pieces (99.99\%) were melted in an induction furnace and then cast to a cylindrical ingot. After hot forging and hot rolling, the Ni9W alloy slab has been processed by heavy cold rolling. In order to strengthen the cube texture, the intermediate recovery treatment has been carried out during the rolling process. Thus, both the single recovery treatment and the multi-recovery treatment have been inserted into the cold rolling processes. For one time 
TABLE I

Thermo-Mechanical Rolling Processes of the Multi-Recovery ROLLING TECHNIQUE IN Ni9W TAPES

\begin{tabular}{|c|c|}
\hline $\begin{array}{l}\text { Recovery } \\
\text { Times } \\
\end{array}$ & $\begin{array}{l}\text { Thermo-mechanical rolling processing } \\
(99 \% \text { total rolling reduction })\end{array}$ \\
\hline$\overline{\text { One }}$ & $60 \%$ cold rolling $\left(500^{\circ} \mathrm{C} / 2 \mathrm{~h}\right)+97.5 \%$ cold rolling; \\
\hline Two & $\begin{array}{l}60 \% \text { cold rolling }\left(500^{\circ} \mathrm{C} / 2 \mathrm{~h}\right)+60 \% \text { cold rolling }\left(500^{\circ} \mathrm{C} / 2 \mathrm{~h}\right) \\
+93.75 \% \text { cold rolling; }\end{array}$ \\
\hline Three & $\begin{array}{l}60 \% \text { cold rolling }\left(500^{\circ} \mathrm{C} / 2 \mathrm{~h}\right)+60 \% \text { cold rolling }\left(500^{\circ} \mathrm{C} / 2 \mathrm{~h}\right)+ \\
60 \% \text { cold rolling }\left(500^{\circ} \mathrm{C} / 2 \mathrm{~h}\right)+84.4 \% \text { cold rolling; }\end{array}$ \\
\hline Four & $\begin{array}{l}60 \% \text { cold rolling }\left(500^{\circ} \mathrm{C} / 2 \mathrm{~h}\right)+60 \% \text { cold rolling }\left(500^{\circ} \mathrm{C} / 2 \mathrm{~h}\right)+60 \% \\
\text { cold rolling }\left(500^{\circ} \mathrm{C} / 2 \mathrm{~h}\right)+60 \% \text { cold rolling }\left(500^{\circ} \mathrm{C} / 2 \mathrm{~h}\right)+60 \% \text { cold } \\
\text { rolling; }\end{array}$ \\
\hline
\end{tabular}

recovery treatment, the intermediate annealing performed using the same processing parameters with the Ni7W alloy, i.e., after $90 \%$ cold rolling reduction, the sheet was annealed at $500^{\circ} \mathrm{C}$ for $2 \mathrm{~h}$ followed by additional $90 \%$ cold rolling to a final thickness of $90 \mu \mathrm{m}$ [9]. Table I shows the detailed thermo-mechanical parameters of the multi-recovery annealing experiment. The recovery was carried out one, two, three and four times after every $60 \%$ cold rolling reduction at $500^{\circ} \mathrm{C}$ for $2 \mathrm{~h}$ for each specimen, respectively. The starting thickness is calculated based on the thickness at the last annealing. For each rolling process, the total rolling reduction was $99 \%$, the pass reduction being below $5 \%$.

The deformation texture was investigated with a X-ray texture goniometer as well as with a SEM, equipped with an electron back scattering diffraction (EBSD) detector. The rolled Ni9W tapes were heat treated by a two-step annealing process [10] in a flowing $\mathrm{Ar}-4 \% \mathrm{H}_{2}$ atmosphere (i.e., annealed at $1100^{\circ} \mathrm{C}$ for $60 \mathrm{~min}$ following treatment at $700^{\circ} \mathrm{C}$ for $30 \mathrm{~min}$ ) in order to get the desired orientation. The recrystallization texture was characterized by EBSD; the measurement area was $800 \mu \mathrm{m} \times$ $800 \mu \mathrm{m}$, while the scanning step size was $2 \mu \mathrm{m}$.

\section{RESULTS}

\section{A. Effect of the Single Recovery Annealing Cycle on the Cube Texture Formation in Ni9W Tapes}

Due to the efficiency of the single recovery treatment on sharpening the cube texture in Ni7W substrate [9], the formation of the recrystallization cube texture in Ni9W tapes was firstly carried out using the same rolling parameters as in Ni7W substrates, i.e., annealing at $500^{\circ} \mathrm{C}$ for $2 \mathrm{~h}$ after $90 \%$ cold rolling followed by an additional $90 \%$ cold rolling reduction.

Fig. 1 shows the (111) pole figures of the deformed Ni9W substrate without (Fig. 1(a)) and with (Fig. 1(b)) the intermediate annealing. It can be seen that these two substrates have the same deformation texture, i.e. both of them are dominated by the Brass orientation, which is the typical preferred deformation orientation for the metal or alloys with low SFE. Thus, no variation of deformation texture derived from intermediate recovery treatment is observed. However, the maximum orientation strength in the substrate with intermediate annealing has been decreased slightly. This could be caused by the additional cold rolling reduction (90\%) in the substrate with intermediate annealing compared with $99 \%$ rolling reduction in the substrate without intermediate annealing.

To investigate the influence of the single intermediate annealing cycle on the cube texture formation, the as-rolled Ni9W
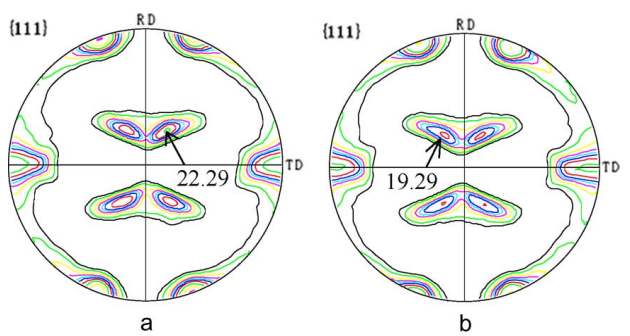

Fig. 1. The (111) pole figures of the deformed Ni9W substrate without (a); with intermediate recovery treatment (b).

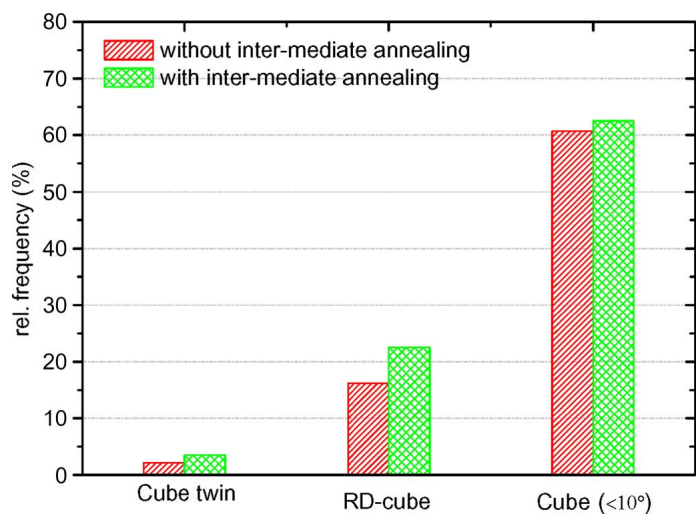

Fig. 2. Recrystallization texture components of the Ni9W substrate with and without intermediate annealing.

substrates with and without recovery annealing were annealed at $1100^{\circ} \mathrm{C}$ for $60 \mathrm{~min}$ using the two-step annealing method. Fig. 2 shows the main recrystallization texture contents in the recrystallized Ni9W substrates. Here, the tolerance angles of Cube $\{001\}\langle 100\rangle$, Cube twins $\{122\}\langle 212\rangle$ and RD rotated cube $\{025\}\langle 100\rangle$ are defined as $10^{\circ}, 10^{\circ}$ and $8^{\circ}$ respectively. It is found that the cube texture content is $60.7 \%$ and $62.5 \%$ for Ni9W substrates, both without and with intermediate annealing, respectively. This means that the effect of single annealing cycle on the cube texture formation in Ni9W substrates may not be efficient. Meanwhile, similar results were observed for cube twining and RD-rotated cube texture. Furthermore, the small content differences between the three recrystallization textures are probably caused by measurement errors. Thus, it can be concluded that the used rolling parameters do not lead to the expected improvement of the cube texture formation in Ni9W substrate.

\section{B. Effect of Multi-Recovery Annealing on the Cube Texture Formation in Ni9W Tapes}

To produce more cube texture in Ni9W substrates, the rolling process should be optimized to favor the cube texture formation. Due to the lower SFE in Ni9W compared to Ni7W alloy, the multi-recovery annealing technique has been considered as favorable, while the cold rolling reduction prior to the recovery treatment has been decreased from $90 \%$ to $60 \%$.

Fig. 3 shows the deformation texture of the Ni9W substrates with different intermediate recovery cycles. It is found that both the $C\{112\}\langle 111\rangle$ and $S\{123\}\langle 634\rangle$ orientation increased with the number of annealing cycles, while the $\mathrm{S}$ orientation decreased to a certain extent in the substrate with four intermediate annealing cycles when compared with that in the three 

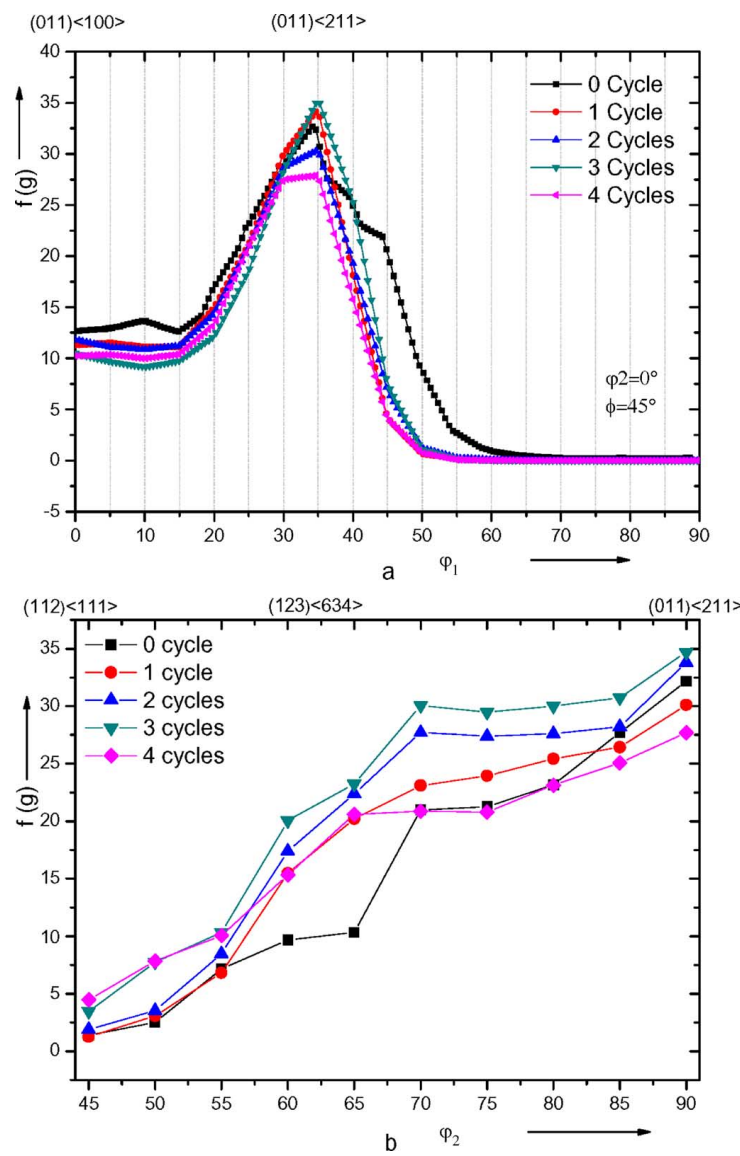

Fig. 3. The $\alpha$-fiber (a); and $\beta$-fiber (b) of the deformed Ni9W substrates with different recovery annealing cycles during cold rolling.

cycle treatment. At the same time, the Goss $\{011\}\langle 100\rangle$ orientation decreased. This is encouraging because both the $\mathrm{C}$ and $\mathrm{S}$ orientation are beneficial for the formation of cube texture on recrystallization. However, the $\operatorname{Br}\{011\}\langle 112\rangle$ orientation does not seem to depend on the number of recovery cycles. Nevertheless, it can be concluded that the deformation texture has been improved by the intermediate recovery during the cold rolling process.

The cube texture content of the Ni9W substrate annealed at $1100^{\circ} \mathrm{C}$ for $1 \mathrm{~h}$ using the two-step annealing method is presented in Fig. 4 as a function of the number of recovery cycles. It is clear that the recrystallized cube texture increased with increasing the number of intermediate treatments up to three recovery cycles, but decreases slightly or keeps the same level in the substrate with four cycles of intermediate recovery annealing. This indicates that the cube texture formation is not monotonically related to the number of recovery cycles. The highest cube texture content (within a misorientation angle of $10^{\circ}$ ) is $76 \%$, which is $16 \%$ higher than that of a traditional cold rolled substrate. Therefore, it is deduced that the multi-recovery treatment favors the formation of the cube texture in Ni9W alloy.

To further strengthen the cube texture in the Ni9W substrate, the three-step annealing method [11] in which a recovery annealing step is added before the first annealing step in the twostep annealing method has been employed to anneal the substrate. After a three step annealing, the cube texture content of

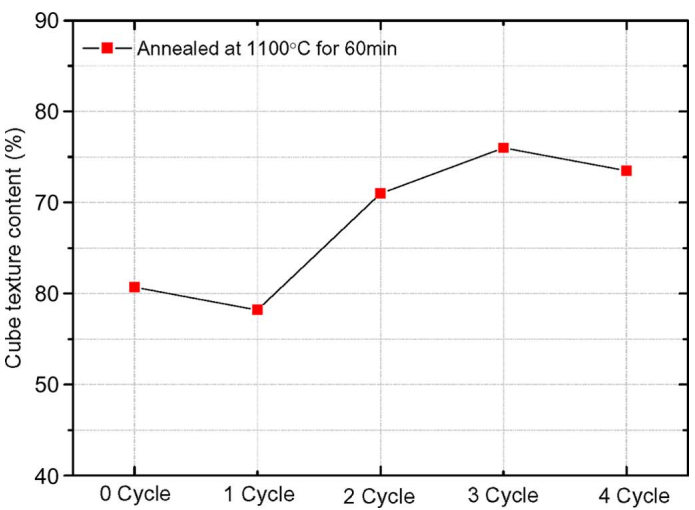

Fig. 4. The cube texture content as a function of the number of recovery cycles in the annealed Ni9W substrates.

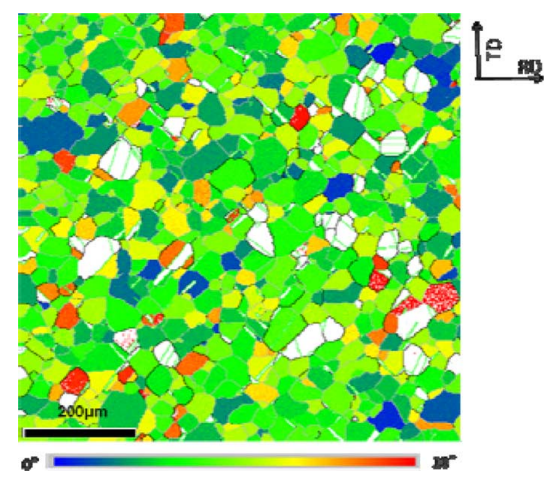

Fig. 5. EBSD map of the Ni9W substrate annealed at $1100^{\circ} \mathrm{C}$ using the threestep annealing method.

the Ni9W substrate can reach $87.7 \%\left(<10^{\circ}\right)$ (Fig. 5), which is an exciting result for an alloy with such a low SFE. It is reasonable to deduce that the multi-cycle recovery annealing is a promising technique to produce sharp cube texture for satisfying the requirement of epitaxial growth in the Ni9W alloy substrate.

\section{DISCUSSION}

The formation of cube texture in fcc metals can be explained by the ON and OG theories [3]-[5]. According to these theories, the cube texture is preferentially formed in the Copper-type deformation texture. In the present work, the deformation texture has been influenced by the number of intermediate annealings. The ratio (R) has been calculated between the sum of $\mathrm{C}$ and $\mathrm{S}$ texture contents and the content of $2 \mathrm{Br}$ texture [2], the value characterizing the deformation texture transition from copper-type to Brass-type deformation texture. To estimate the deformation texture dependence on the number of recovery cycles, Fig. 6 shows the $\mathrm{R}$ value as a function of the number of recovery cycles. It is found that the $\mathrm{R}$ value increases with the number of recovery cycles, which indicates there is more copper-type deformation texture in the recovered substrate. This is also observed in Aluminum alloys after additional annealing [12]. For the Ni9W alloy, the additional copper-type texture could be attributed to the released work-hardening during intermediate recovery, which is related to the deformation texture transition in low SFE metal or alloys [13]. However, the $\mathrm{R}$ value did not continuously increase after four recovery cycles. This is probably caused by the low additional cold rolling reduction 


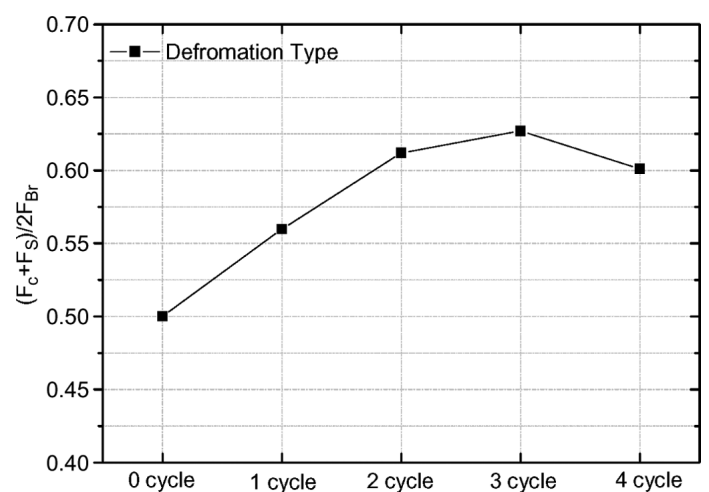

Fig. 6. Value of $\mathrm{R}$ as a function of the number of recovery cycles.

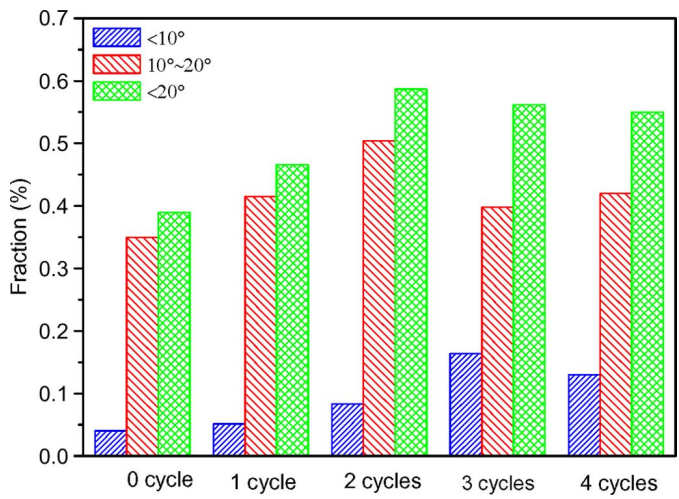

Fig. 7. The cube-oriented texture in deformed Ni9W substrates, depending on the number of recovery cycles.

(60\%) after the last annealing treatment which is not sufficient to develop the deformation texture well. Indeed, this result could explain the decrease of the recrystallized cube texture in the substrate with four recovery cycles (Fig. 4).

On the other hand, the cube texture formation is also related to the pre-existing cube-oriented structure in the deformed matrix according to the $\mathrm{ON}$ theory. The pre-existing cube oriented structure furnishes the original nucleation sites to form the cube texture because it can undergo rapid static and dynamic recovery due to its unique dislocation arrangement [14]. In Fig. 7 the cube texture $\left(<0^{\circ}\right)$ and near cube texture $\left(<20^{\circ}\right)$ have been represented in the deformed Ni9W substrate for various numbers of recovery annealing cycles. It can be seen that the cube texture and near cube texture are increasing with increasing recovery cycle number, up to $n=3$. This is probably due to that the recovered cube structure after one cycle annealing has to suffer heavily additional cold rolling (97.5\% of the substrate with one cycle treatment) process that perhaps splits or rotates some of the recovered cube grains [15]. Thus, the inclusion of more recovery cycles in the cold rolling process is necessary for the recovery the splited or rotated cube structures. Therefore, a higher amount of cube structure can survive up to the final deformed structure with the increasing number of recovery cycles until the additional cold rolling could not split or rotate the recovered cube structure. But there is a limit of the final additional cold rolling reduction to ensure the size advantage of the cube oriented structure compared with other orientation structures, due to its higher stability during the rolling process [16]. From Figs. 4 and 7, it can be concluded that the optimum treatment consists in carrying out three recovery cycles during the cold rolling process.

\section{CONCLUSIONS}

In this work, a multi-recovery annealing process has been carried out during traditional cold rolling process, the recrystallized cube texture being strengthened upon recrystallization. The following conclusions are drawn:

1) The single recovery cycle which has obviously improved the cube texture formation in the Ni7W substrate is not suitable for Ni9W substrate due to the lower SFE;

2) A sharp cube texture (87.7\%) has been obtained using a rolling technique with three recovery cycles and optimized three-step annealing method;

3) The mechanism of strengthening the cube texture formation by intermediate anneals relies on the improvement of the copper-type deformation texture as well as the increase of the pre-existing cube oriented structure in deformed matrix;

4) Multi-recovery technique is a promising solution to produce sharp cube texture in Ni-W alloy with high $\mathrm{W}$ contents.

\section{REFERENCES}

[1] J. Eickemeyer, D. Selbmann, R. Opitz1, B. de Boer, and B. Holzapfel et al., "Nickel-refractory metal substrate tapes with high cube texture stability," Supercond. Sci. Technol., vol. 14, pp. 152-159, 2001.

[2] I. V. Gervasyeva, D. P. Rodionov, B. K. Sokolov, and Y. V. Khlebnikova, "Effect of deformation texture component composition on cube texture formation during primary recrystallization in Ni-based alloys," in Mater. Sci. Forum, 2005, vol. 495-497, pp. 1213-1218.

[3] $\mathrm{H}$. Hu, "Nucleation of recrystallization for cube texture formation in FCC metals," Annealing Processes: Recovery, Recrystallization and Grain Growth, Proc. 7th Riso Int. Symp. Metallurgy Mater. Sci., pp. 75-96.

[4] R. D. Doherty, "Recrytallization and texture," Progr. Mater. Sci., vol. 42, pp. 39-58, 1997.

[5] R. D. Doherty, D. A. Hughes, F. J. Humphreys, J. J. Jonas, and D. Juul Jensen et al., "Current issues in recrystallization: A review," Mater. Sci. Engi. A, vol. 238, pp. 219-274, 1997.

[6] Y. X. Zhou, S. V. Ghalsasi, M. Hanna, Z. J. Tang, and R. L. Meng et al., "Fabrication of cube-oriented Ni-9\%atW substrate for YBCO superconducting wires using poeder metallurgy," IEEE Trans. Appl. Surpercond., vol. 17, pp. 3428-3431, 2007.

[7] J. Eickemeyer, R. Huhne, A. Guth, C. Godig, and H. Klaub et al., "Textured Ni-7.5at\%W substrate tapes for YBCO coated conductors," Supercond. Sci. Technol., vol. 21, pp. 1-7, 2007.

[8] Data presented at superconductivity for electric systems, Washington, DC, 2003 Annual Peer Review, Jul. 23-25, 2003.

[9] M. M. Gao, H. L. Suo, Y. Zhao, J.-C. Grivel, and P. K. Gao et al., "Influence of the inter-mediate annealing on the cube texture formation in Ni-7at.\%W substrate for coated conductors," 2010, under submitting.

[10] M. M. Gao, H. L. Suo, Y. Zhao, Y. H. Zhu, L. Ma, and R. F. Fan et al., "Investigation of texture formation in Ni-7at.\%W alloy substrates by spark plasma sintering technique," IEEE Trans. Appl. Supercind., vol. 19, pp. 3279-3282, 2009.

[11] M. M. Gao, H. L. Suo, Y. Zhao, J.-C. Grivel, and L. Ma et al., Investigation of the Annealing Method on Cube Texture Formation in Ni-9at.\%W Substrate under submitting, 2010.

[12] X. M. Zhang, Y. Q. Xiao, J. G. Tang, Z. Y. Chen, and S. D. Liu et al., "Influence of pre-annealing and additional deformation on the recrystallization texture of high purity aluminum folis," in Materials Science Forum, 2002, vol. 408-412, pp. 1443-1448.

[13] T. Leffers and R. K. Ray, "The brass-type texture and its deviation from the copper-type texture," Progr. Mater. Sci., vol. 54, pp. 351-396, 2009.

[14] A. A. Ridha and W. B. Hutchinson, Acta Metall, vol. 30, p. 1929, 1982.

[15] X. M. Zhang, S. D. Liu, J. G. Tang, and Z. P. Zhou, "Mechanism of strengthening of cube texture for high purity aluminum foils by additional annealing," Trans. Nonferrous Met. Soc. China, vol. 13, pp. 499-503, 2003.

[16] O. Daaland and E. Nes, "Origin of cube texture during hot rolling of commercial Al-Mn-Mg alloys," Acta. Mater., vol. 44, pp. 1389-1411, 1996. 